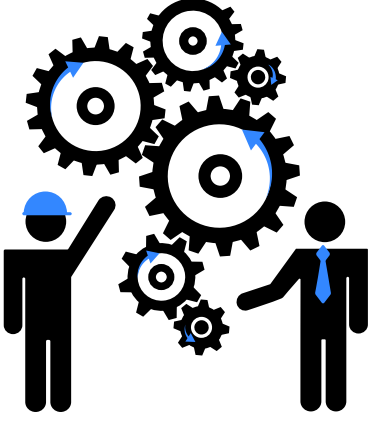

\section{APLICACIÓN MÓVIL PARA LA PROMOCIÓN Y PUBLICIDAD DEL TURISMO EN LA CIUDAD DE HUANCAYO}

Gary Risco Reyes ${ }^{1}$, Pedro Castañeda Vargas ${ }^{2}$ ${ }^{1}$ Universidad Continental, Facultad de Ingeniería, EAP Ing. de Sistemas e Informática;
Correo electrónico: garyriscoreyes@gmail.com
${ }^{2}$ Universidad Continental, Facultad de Ingeniería, EAP Ing. de Sistemas e Informática;
Correo electrónico: pcastaneda@continental.edu.pe

Resumen - La ciudad de Huancayo recibe un gran número de turistas extranjeros y nacionales, un promedio de medio millón de entusiastas anualmente. Por ello surge la necesidad de mostrar a los visitantes los lugares importantes de la ciudad, como el centro y sus alrededores. Se mejoró esta tarea mediante el desarrollo de una aplicación móvil que informa acerca de ciertos lugares representativos del centro histórico, así como de sus alrededores, con ella el turista obtiene más información del lugar que está visitando.

La solución fue muy viable, ya que, en los últimos años, disponer de un dispositivo inteligente se ha convertido en una necesidad del día a día.

Los aspectos antes mencionados facilitaron que casi cualquier persona pueda acceder a la aplicación turística para el centro histórico de la ciudad de Huancayo.

La aplicación, programada en Android, utilizó información seleccionada para ayudar al usuario a reconocer los diferentes sitios turísticos que existen en el centro histórico y conocer los principales detalles de estos.

La aplicación da al turista referencias exactas de la ubicación del siguiente punto de interés en promociones, tomando en cuenta las opciones de restaurantes y hoteles en la ciudad en ese momento. Con esta aplicación el turista no requirió tener un guía de turismo para aprender sobre el lugar que está visitando.

Palabras clave: Aplicación Android; aplicación móvil; turismo; desarrollo de software; sistema informático.

\section{INTRODUCCION}

Según el registro de los operadores turísticos, entre el 1 y el 3 de mayo del 2015, atendieron alrededor de 800 turistas, de los cuales 250 turistas, entre nacionales y extranjeros, llegaron por tren, número inferior al esperado. Por ello, el personal de la Agencia de Viajes Peruvian Tours manifestó que la Dircetur no realiza un trabajo óptimo para promocionar los atractivos turísticos, lo que trae como consecuencia que Huancayo reciba menos visitantes. Se señaló que el número de turistas disminuye considerablemente cada año [1]

Se han realizado algunas iniciativas por parte de los gobiernos regionales y algunas municipalidades, que invierten parte de su presupuesto en el sector turismo, brindándole una

\begin{abstract}
The city of Huancayo has a large number of foreign and domestic tourists, amount half a million annually Thus the need arises to show visitors the important places in the city, such as the center from the city. This task was improved by developing a mobile application that reports on some important sites of the historic center as well as its surroundings, so that the tourists could learn more about the place they're visiting.
\end{abstract}

The solution was very viable since in recent years a smart device has become a necessity of day

The aforementioned aspects provided that almost anyone can access the app tourist center of the city of Huancayo The selected application, programed in Android, used to help the user to recognize that there are various tourist sites in the historic center and visit the main details of these information

The application gave the tourists a reference of where the next point of interest in promotion, taking into account the choices of restaurants and hotels in the city at that time. With this application, tourists did not require to have a tour guide to learn about the place they're visiting.

Keywords: Android application; mobile application; tourism; software development; informatics

herramienta, tan importante e indispensable en nuestros días, como la iniciativa de Promperu llamada Guía de servicio Turístico, disponible para descubrir los servicios turísticos como hoteles, restaurantes, etc., creada el 2014

Otra de las iniciativas respaldadas por la inversión privada de Odebrecht es la llamada "Interoceánica completa tu mundo", también creada en el 2014, que presenta información en cinco secciones del recorrido, con detalles actualizados de sus atractivos turísticos, servicios existentes, mapas y recomendaciones de viaje.

Lo principal en los medios de difusión utilizados actualmente es que hay una gran tendencia a trabajar todo el esquema de dispositivos móviles, motivado por el uso que se le da. 
La actividad tecnológica está en pleno auge de crecimiento desde hace varios años en todo el mundo. Actualmente, esta área de la industria apuesta por el turismo con el objetivo de mejorar la experiencia y atraer más turistas a Perú.

El avance constante en el desarrollo de las tecnologías, especialmente las que tienen relación con la información y la comunicación, el número creciente de usuarios de móviles, junto con el aumento en las tasas turísticas, hicieron necesario volver a pensar las estrategias de negocios, objetivos y canales de distribución de la información.

El turista demanda tecnologías que le ayuden a ganar tiempo y mejoren su experiencia de viaje. Qué mejor manera de obtener difusión a través de la tecnología que se lleva todo el tiempo en los bolsillos. Por ello se planteó el desarrollo de una aplicación móvil turística, que considere la promoción y publicidad en la ciudad de Huancayo con información de hoteles, restaurantes y sitios turísticos.

En el presente trabajo se explica el uso de la metodología de gestión de proyectos Scrum, se presentan las herramientas utilizadas para desarrollar la aplicación y se muestra el prototipo terminado, lo que se consiguió en escasas semanas.

Si por algo se caracteriza Scrum es por aplicar una mejora continua constante, permite saber en qué punto del proyecto se encuentra y si se ha detectado algún mal funcionamiento está la posibilidad de cambiarlo, así como las pruebas de usabilidad realizadas y los resultados obtenidos.

\section{ANTECEDENTES}

Los antecedentes que se presentan a continuación se citarán de manera descriptiva, fueron revisados y analizados para brindar mayor consistencia teórica a este trabajo de investigación.

A modo de referencia, se considerará el aporte de Trinidad Pozo Borrego con su tesis Tecnologías móviles y turismo. realizada en la Universidad de Málaga en junio del 2014 [2]. La tesis describe el desarrollo que ha tenido el turismo en la Internet, un fenómeno que ha revolucionado el mundo y con ello la forma de vida del consumidor, quien cada vez hace un mayor uso, a través de numerosas aplicaciones móviles, del smartphone o las tabletas para buscar información, reservar vuelos, compartir experiencias en sus viajes, entre otras actividades.

Esta herramienta tecnológica hoy en día es indispensable para el turismo, tanto es así que, a través del estudio realizado, la mayoría de los destinos turísticos españoles cuentan con una aplicación móvil orientada al turismo, la cual ha sido desarrollada por un organismo público. Sin embargo, es importante destacar que no todos estos destinos han desarrollado una aplicación enfocada a los turistas internacionales por lo que deben de apostar más en ello.

El objetivo principal de este trabajo fue conocer, mediante un estudio analítico previo, en qué situación se encuentra el territorio español en cuanto al desarrollo de aplicaciones turísticas de carácter oficial que hayan sido creadas por un organismo público.

El mismo estudio revela que los smartphone, como herramienta de compra, son utilizados en un $82 \%$ por los consumidores, los cuales han buscado un producto o servicio a través de su dispositivo móvil.
Esta búsqueda influye posteriormente en las decisiones del comprador (compra o no de un producto o servicio online o en el establecimiento), así como en las compras en diferentes canales: por ordenador (41\%) o directamente en la tienda (31\%).

Se dice que los compradores desde smartphone son compradores habituales y un $63 \%$ de españoles afirma que realiza compras desde su teléfono móvil al menos una vez al mes (IPSOS MediaCT, 2013). Aunque esta modalidad de compra está en auge, también existen algunas barreras con respecto al comercio móvil que aún deben solucionarse.

Así, debido a las numerosas oportunidades y ventajas que pueden ofrecer el uso de estas aplicaciones móviles, es necesario tener un profundo entendimiento para explotar al máximo todo el potencial que se deriva de estas herramientas, las cuales están presentes en la vida diaria de un turista que está cada vez más conectado a través de los distintos dispositivos móviles electrónicos como los smartphone y las tabletas, además exige compartir sus experiencias en el momento en que las vive.

Otro antecedente es el proyecto "Integración de Foursquare y geolocalización en una Aplicación móvil para la creación de rutas turísticas" [3] realizado por Manuel Eduardo Sánchez Gomis de la Universidad Politécnica de Valencia, a inicios del 2015. Este trabajo tuvo como objetivo desarrollar una aplicación que permitiera crear rutas turísticas a los usuarios. Esta aplicación proporciona, principalmente, tres funcionalidades: la creación de una ruta turística, su finalización y publicación en un servidor web y la descarga y el seguimiento punto a punto de una ruta. Con este objetivo, la aplicación móvil integra varias tecnologías: geolocalización, redes sociales y servicios web.

Todas ellas se han desplegado en un dispositivo móvil Android que ha enriquecido la aplicación móvil a realizar.

La realización de esta aplicación plantea una serie de objetivos:

- Necesidad de obtener un conjunto de datos para poder realizar las rutas turísticas. Estos deben estar en constante actualización para que el proyecto no quede obsoleto.

- La información obtenida anteriormente debe ser mostrada al usuario de manera clara, para que éste pueda interactuar con ella sin que le resulte tedioso y complicado.

- El usuario debe poder complementar la anterior información con una nueva información, lo que permite ampliar los datos mostrados.

- La información introducida por el usuario debe ser almacenada para futuras consultas.

- La información almacenada por el usuario debe ser fácilmente accesible por otros usuarios.

La aplicación móvil que se presenta como solución a las necesidades anteriores utiliza e integra diferentes tecnologías.

En primer lugar, la aplicación se integra con la red social Foursquare, una red social especializada en lugares, sitios de 
ocio o de visita. La integración con esta red social permite que la aplicación muestre, utilice e incluya este conjunto de datos para la creación de rutas turísticas. En segundo lugar, la aplicación está basada en la localización del usuario.

Esto significa que los puntos o lugares de ocio se obtienen en función de la posición de éste. Finalmente, la aplicación se integra con un servidor web en el que los usuarios pueden publicar las rutas creadas. De esta manera, un usuario puede buscar, descargar y recorrer rutas creadas por otros usuarios.

Integrando todas estas tecnologías se ha desarrollado una aplicación que permite crear rutas turísticas. Este proceso se inicia cuando el usuario crea una ruta de viaje nueva. Una vez creada, obtiene su posición mediante el uso de la geolocalización. Esta información es enviada a Foursquare, que filtra los puntos almacenados en su red social y los devuelve al dispositivo.

Utilizando estos puntos y añadiendo información adicional, como comentarios o valoraciones de los lugares, el usuario construye su ruta punto a punto. Una vez finalizada su ruta, esta es enviada al servicio web para que sea almacenada y permita a otros usuarios descargarla y seguirla, además de disfrutar las experiencias vividas por este.

Y por último, se citará el trabajo de Ramón Núñez del Arco (Universidad Católica de Santiago de Guayaquil, 2013), titulado "Aplicativo para dispositivos móviles sobre información turística y hotelera de la ciudad de Guayaquil" dirigido a turistas nacionales y extranjeros" [4]. Este proyecto además de brindar un beneficio exclusivo a visitantes que se encuentren en la ciudad, busca incrementar y explotar el turismo de la misma, y apoyar al país desde un punto de vista cultural y económico, puesto que muchas atracciones, pequeños y grandes negocios e industrias hoteleras, se beneficiarían con este nuevo medio y canal de promoción de sus negocios.

Debido a la gran demanda de dispositivos móviles las personas hoy en día usan el internet móvil de sus smartphones (iPhone, BlackBerry, Nokia y otros) para ingresar en la web, para descargar imágenes y datos, ver contenidos de interés y buscar información en cualquier lugar.

Por lo tanto, se han presentado diferentes problemas a quienes lo frecuentan:

- Dificultad en ver sitios web, por menú de texto y contenido muy pequeño.

- Las empresas carecen de apps móviles para mostrar sus productos y servicios

- La página se carga más lenta.

- Dificultad para lograr ver el sitio web de la empresa hotelera correctamente en la pantalla del dispositivo, no permite visualizar imágenes o banners animados etc.

- Información desactualizada o fraudulenta.

- Aglomeración de personas en hoteles preferidos porque no conocen otros que ofrezcan el mismo servicio. comodidad o presupuesto.
- Información incorrecta, desactualizada, errónea y fraudulenta en Internet.

- Ignorancia de las actividades festivas en la ciudad.

- Desinformación sobre actividades y eventos en el hotel.

\section{DEFINICIÓN DE TÉRMINOS BÁSICOS}

OMT: Siglas de la Organización Mundial del Turismo. Entidad que genera conocimiento de los mercados, promueve políticas e instrumentos de turismo competitivo y sostenible, fomenta la enseñanza y la formación en materia de turismo y trabaja con el fin de hacer del turismo una herramienta eficaz para el desarrollo mediante proyectos de asistencia técnica en más de 100 países del mundo [5].

Sistema operati vo Android: Es un conjunto de herramientas y aplicaciones. Por sí solo no es un sistema operativo. Android es de código abierto, gratuito y no requiere pago de licencias. También es una plataforma de código abierto para dispositivos móviles que está basada en Linux y desarrollada por Open Handset Alliance. Compañías poderosas, como LG, Motorola y HTC, ya han diseñado alguno de los prototipos que incorporarán al sistema Android.

ECLIPSE: Es una plataforma de desarrollo, diseñada para ser extendida de forma indefinida a través de plug-ins. Fue concebida desde sus orígenes para convertirse en una plataforma de integración de herramientas de desarrollo libre.

SDK: El SDK de Android proporciona las diferentes bibliotecas API y las herramientas útiles de desarrollo necesarias para crear, probar y depurar aplicaciones para Android.

APK: Es un paquete para el sistema operativo Android; se usa para distribuir e instalar componentes empaquetados para la plataforma Android para smartphones y tabletas.

IDE: Un integrated development environment (IDE), por sus siglas en inglés. El ambiente de desarrollo interactivo o entorno de desarrollo integrado es una aplicación de software, que proporciona servicios integrales para facilitarle al programador de computadora el desarrollo de software.

MVC (modelo-vista-controlador): Es un patrón de arquitectura de software que separa los datos y la lógica de negocio de una aplicación de la interfaz de usuario.

HTML5 (HyperText Markup Language, versión 5): Es lenguaje básico de la World Wide Web que establece una serie de nuevos elementos y atributos que reflejan el uso típico de los sitios web y móviles modernos.

CSS3 (cascading style sheets, versión 3): La hoja de estilo en cascada es un lenguaje usado para definir y crear la presentación de un documento estructurado escrito en HTML. 


\section{SCRUM}

La palabra Scrum proviene del nombre de una jugada que ocurre en los partidos de rugby. Scrum es una metodología ágil en la cual se llevan a cabo una serie de prácticas iterativas, cuyo objetivo es que el grupo de desarrolladores trabaje unido, contribuyendo con sus habilidades individuales para la obtención de un software de buena calidad.

Una de las características de Scrum es la entrega de porciones incrementales del producto final al término de cada iteración; de esta manera, se pueden ir haciendo modificaciones o continuar con el desarrollo del software tal como se tenía previsto originalmente.

Scrum es una metodología diseñada para el desarrollo de productos en ambientes complejos en donde se requiere un producto funcional rápidamente, con cambios constantes o con especificaciones ambiguas como en el caso de esta aplicación.

En un equipo de Scrum existen tres diferentes roles: el propietario del producto, el Scrum máster y los miembros del equipo (ver Tabla n. ${ }^{\circ}$ 1). Dentro del marco general de Scrum existen reuniones que ayudan a la planeación del desarrollo en donde las experiencias adquiridas por los desarrolladores son muy relevantes, por lo que la retroalimentación y la recopilación de historias son fundamentales (ver Tabla n. ${ }^{\circ}$ 2)

El Sprint es el ciclo fundamental (iteración) del proceso de Scrum (ver Figura 1). Scrum no especifica la longitud del sprint de su equipo, pero se considera que una semana es el tiempo máximo para esta aplicación turística. Dos semanas es la longitud más frecuente, aunque también es común encontrar sprints con longitud de entre una y tres semanas.

Tabla n. ${ }^{\circ}$. Roles principales del scrum

\begin{tabular}{|c|c|}
\hline Rol & Descripción \\
\hline $\begin{array}{l}\text { Propietario del } \\
\text { producto } \\
\text { (Product } \\
\text { owner }\end{array}$ & $\begin{array}{l}\text { Se asegura de que las necesidades de los } \\
\text { clientes y usuarios finales son comprendi- } \\
\text { das por el equipo. Hace esto directamente } \\
\text { creando, perfeccionando y comunicando } \\
\text { los requisitos. }\end{array}$ \\
\hline $\begin{array}{l}\text { Maestro } \\
\text { Scrum } \\
\text { (Scrum Mas- } \\
\text { ter) }\end{array}$ & $\begin{array}{l}\text { Una de sus principales funciones es la im- } \\
\text { plementación de cada una de las caracterís- } \\
\text { ticas de Scrum, también es un facilitador el } \\
\text { cual se asegura de eliminar los problemas } \\
\text { que pueda llegar a tener el equipo. }\end{array}$ \\
\hline $\begin{array}{l}\text { Equipo de } \\
\text { desarrollo }\end{array}$ & $\begin{array}{l}\text { Los equipos son altamente colaborativos, } \\
\text { también se auto-organizan. Los miembros } \\
\text { del equipo tienen autoridad total sobre } \\
\text { cómo se hace el trabajo. Las personas que } \\
\text { hacen el trabajo son las más autorizadas } \\
\text { para decidir la mejor forma de hacerlo. }\end{array}$ \\
\hline
\end{tabular}

Tabla n. ${ }^{\circ}$ 2. Reuniones en Scrum

\begin{tabular}{|c|c|}
\hline Reunión & Descripción \\
\hline $\begin{array}{l}\text { Scrum diario } \\
\text { (Daily Scrum) }\end{array}$ & $\begin{array}{l}\text { Es una reunión diaria, generalmente al inicio del } \\
\text { periodo de trabajo, que se puede adaptar a las } \\
\text { necesidades del equipo. De manera breve cada } \\
\text { participante comparte: } \\
\text { Lo que ha completado desde el último Daily } \\
\text { Scrum } \\
\text { Lo que espera completar para el siguiente Daily } \\
\text { scrum } \\
\text { Los obstáculos que ha tenido durante el desa- } \\
\text { rrollo }\end{array}$ \\
\hline $\begin{array}{l}\text { Scrum de } \\
\text { scrum }\end{array}$ & $\begin{array}{l}\text { Esta reunión ocurre al finalizar el Daily scrum. } \\
\text { Acuden los líderes de grupo especializados en } \\
\text { un área de desarrollo. Cada participante com- } \\
\text { parte } \\
\text { Lo que ha completado su equipo desde la última } \\
\text { reunión } \\
\text { Lo que espera que complete su equipo para la } \\
\text { siguiente reunión } \\
\text { Los obstáculos que ha tenido su equipo }\end{array}$ \\
\hline $\begin{array}{l}\text { Reunión de } \\
\text { planeación } \\
\text { del Sprint } \\
\text { (Sprint Plan- } \\
\text { ning Meeting) }\end{array}$ & $\begin{array}{l}\text { El Sprint Planning Meeting marca el principio del } \\
\text { sprint. Comúnmente tiene dos partes. El objetivo } \\
\text { de la primera parte es que el equipo se compro- } \\
\text { meta a un conjunto de metas para el sprint. Du- } \\
\text { rante la segunda parte de la reunión, el equipo } \\
\text { identifica las tareas que deben realizarse en el } \\
\text { orden de las historias de usuario acordadas. }\end{array}$ \\
\hline $\begin{array}{l}\text { Reunión de } \\
\text { revisión del } \\
\text { Sprint (Sprint } \\
\text { Review Mee- } \\
\quad \text { ting) }\end{array}$ & $\begin{array}{l}\text { Al final del sprint, el equipo tiene la oportuni- } \\
\text { dad de mostrar su trabajo en el Sprint Review. } \\
\text { El equipo muestra las historias que fueron com- } \\
\text { pletadas y las que faltaron por completar. En } \\
\text { esta etapa es cuando el propietario del produc- } \\
\text { to toma nota del trabajo realizado, revisando las } \\
\text { características solicitadas por el cliente y eva- } \\
\text { luando si es necesario realizar cambios o agregar } \\
\text { nuevas características. }\end{array}$ \\
\hline $\begin{array}{l}\text { Retrospectiva } \\
\text { (Retrospec- } \\
\text { tive) }\end{array}$ & $\begin{array}{l}\text { La retrospectiva se lleva a cabo en la final de } \\
\text { cada sprint, consiste en dedicar tiempo para que } \\
\text { el equipo se enfoque en lo que se ha aprendido } \\
\text { durante el sprint. Esta retroalimentación puede } \\
\text { ser útil para hacer algunas mejoras. }\end{array}$ \\
\hline
\end{tabular}

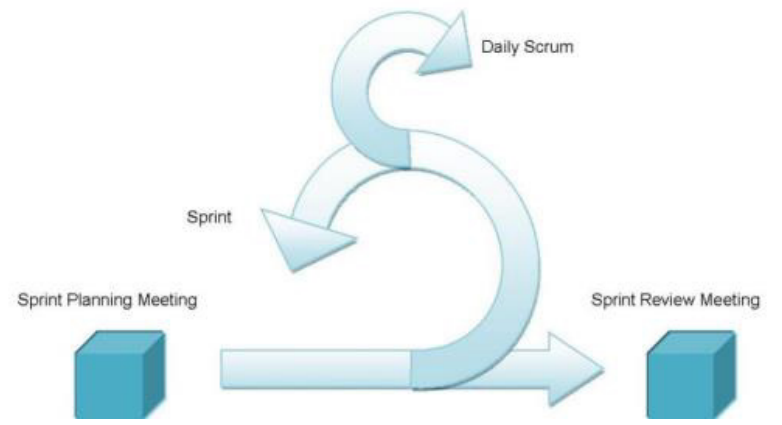

Figura 1. Visión general de Scrum

Fuente: Scrumguides.org. 
Se realizó el desarrollo del software interpretando todos los roles de la metodología Scrum. El objetivo fue construir una aplicación didáctica para Android utilizando el entorno Eclipse con referencia a herramientas libres y siguiendo la metodología ágil denominada Scrum.

La búsqueda de información proporcionó los requerimientos concretos de manera prescriptiva, simplemente expresó con una perspectiva de usuario final, unas necesidades previamente establecidas. Se organizó el proyecto de acuerdo a los principios de la metodología para extraer los requerimientos, tomar decisiones y asignar responsabilidades, siempre tomando en cuenta los límites de tiempo establecidos.

\section{ARQUITECTURA DE LA SOLUCION}

En esta sección se muestra la arquitectura del sistema y el patrón de diseño que serán utilizados para el desarrollo de la aplicación móvil turística y lograr cumplir con los requerimientos establecidos.

\section{A. Arquitectura Modelo-Vista-Controlador}

Para este proyecto se va a utilizar la arquitectura MVC, esto se hizo para permitir una mayor portabilidad de una aplicación e incluso facilitar su mantenimiento.

Pues si se desea modificar la apariencia de la aplicación, se prestará atención a la capa de la Vista; si se quiere cambiar de sistema de almacenamiento de datos, se prestará atención a la capa del Modelo, y si se requiere portar la aplicación a otra plataforma, se modificará la capa del controlador, al igual que si se desea modificar el código para optimizar el rendimiento [6].

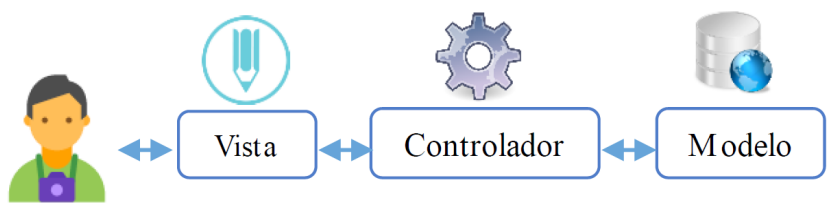

Figura 2. Visión general de MVC Elaboración propia.
Se utilizó este estilo de arquitectura para favorecer su reutilización como servicio de información, también porque proporciona claridad y minimiza el código.

Esto favorece a la aplicación dado que las vistas tienen asociado un enlace URL que permite visualizar las imágenes que están en la web; el controlador permite interactuar con la aplicación por medio de botones y, para finalizar, en el modelo se almacena localmente esta información haciendo la aplicación más ligera.

\section{DISENO DE INTERFAZ GRÁFICA}

Se ha diseñado una aplicación turística para la ciudad de Huancayo.

La aplicación guía a los turistas que vienen a visitar Huancayo y les da información sobre lugares interesantes para visitar.

\section{A. Desarrollo de conceptos}

Se empezó a investigar sobre los sitios turísticos, hoteles y restaurantes para la aplicación de turismo.

El objetivo es crear una experiencia turística única para los turistas que vienen a visitar la ciudad. Se comenzó con la creación de un flujo para la aplicación.

\section{B. Flujo de la aplicación}

Este flujo sirvió como panorama general de la aplicación con los requisitos descritos anteriormente.

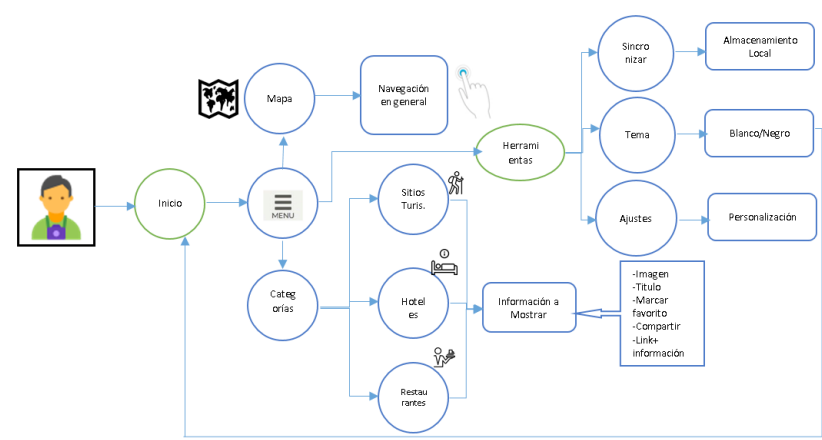

Figura 3. Flujo de la aplicación Elaboración propia.

Por favor, valore las siguientes características de nuestra app, sien do 1 nada importan te y 5 muy

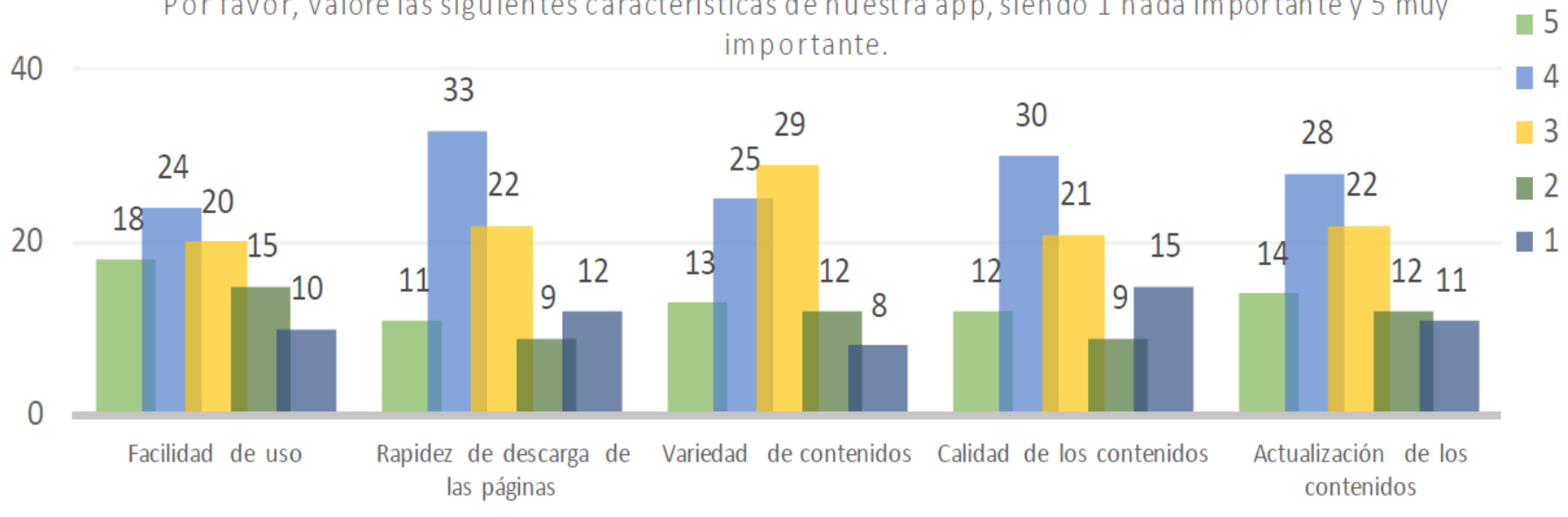

Figura 4. Calificación de la aplicación Elaboración propia. 


\section{Primera fase}

Se crearon bocetos de baja fidelidad, se decidió incluir un mapa donde los usuarios pueden, a través de gestos táctiles, obtener información sobre las calles y lugares populares de la ciudad.

\section{Diseño visual y prototipo}

Antes de crear los diseños visuales se incorporaron las sugerencias:

- Hacer la aplicación lo más simple posible, a fin de que pueda ser utilizada por un joven de 12 años como por una persona de 50 años.

- Después de realizar una búsqueda de información para esta aplicación, se vio que el sitio con mayor relevancia es el nevado Huaytapallana; sin embargo se requiere que los turistas también conozcan otros sitios alternativos en la ciudad. Para resolver este problema, se decidió incluir promociones tanto en hoteles y restaurantes de distintos puntos en la ciudad.

\section{E. Pruebas de usabilidad}

Para determinar la satisfacción del usuario y descubrir los problemas de usabilidad del prototipo, se ha realizado una encuesta de usabilidad en turistas que visitan la ciudad.

En esta investigación se ha utilizado el método probabilístico como método de muestreo, ya que el universo en estudio es finito.

En la figura 4 se muestran los resultados de la prueba de usabilidad. Se obtuvo un buen resultado en la calificación de la aplicación dadas las opiniones en las características que espera el turista.

\section{CONCLUSIONES}

Se adoptó la metodología Scrum para el desarrollo de software la cual culminó con la presentación de un prototipo funcional.

Queda reflejada la viabilidad de aplicar los análisis de usabilidad al desarrollo de plataformas móvil del mismo modo que se puede aplicar a otro tipo de software.
Como trabajo futuro, se plantea agregar al producto turístico nuevas modalidades que puedan captar una mayor recepción de visitantes. Por ejemplo, se debe impulsar la creación de nuevos circuitos turísticos de más amplia envergadura, así los turistas tendrían la oportunidad de conocer el valle del Mantaro, la selva central y sus alrededores.

También, se plantea estudiar los principales segmentos de mercado más atractivos para la compra a través de aplicaciones móviles, la posibilidad de nuevos nichos y si la introducción de ciertas ventajas como descuentos personalizados y cupones familiares fomentaría su uso.

\section{REFERENCIAS BIBLIOGRÁFICAS}

[1] T. Vivanco (2015), Preocupante: Huancayo ya no es destino turístico, Diario Correo [consulta en línea: 15 setiembre 2015]. Recuperado de http://goo.gl/VUA5un.

[2] T. Pozo (2014), Tecnologías móviles y turismo [en línea], Universidad de Málaga, Facultad de Turismo [consulta: 17 setiembre 2015]. Recuperado de http://goo.gl/BYr$7 \mathrm{sm}$.

[3] M. E. Sánchez (2014), Integración de Foursquare y geolocalización en una aplicación móvil para la creación de rutas turísticas [en línea], Universidad Politécnica de Valencia [consulta: 22 setiembre 2015]. Recuperado de https://goo.gl/OAzRHZ.

[4] R. Núñez (2013), Aplicativo para dispositivos móviles sobre información turística y hotelera de la ciudad de Guayaquil dirigido a turistas nacionales y extranjeros [en línea]. Universidad Católicade Santiago de Guayaquil, Facultad de Artes y Humanidades Ingeniería en Sistemas Multimedia [consulta: 01 octubre 2015]. Recuperado de http://goo.gl/96tkn3.

[5] Unwto, acerca de la OMT, Organización Mundial del Turismo, octubre 2015. [consulta: 04 octubre 2015]. Recuperado de http://goo.gl/KHvQjd.

[6] Iavilae (2013), Programación Android, Modelo-Vis ta-Controlador [en línea, consulta: 05 octubre 2015]. Recuperado de http://goo.gl/ODLgoa. 